The Australian Economic Review, vol. 42, no. 1, pp. 24-41

\title{
A Structural Model of Australia as a Small Open Economy
}

\author{
Kristoffer P. Nimark* \\ Economic Research Department, Reserve Bank of Australia
}

\begin{abstract}
This paper sets up and estimates a structural model of Australia as a small open economy using Bayesian techniques. Unlike other recent studies, the paper shows that a small microfounded model can capture the open economy dimensions quite well. Specifically, the model attributes a substantial fraction of the volatility of domestic output and inflation to foreign disturbances, close to what is suggested by unrestricted VAR studies. The paper also investigates the effects of various exogenous shocks on the Australian economy.
\end{abstract}

* The author thanks Jarkko Jaaskela, Christopher Kent, Mariano Kulish, Philip Liu, Adrian Pagan and Bruce Preston for valuable comments and discussions. The views expressed in this paper are those of the author and not necessarily those of the Reserve Bank of Australia.

\section{Introduction}

This paper presents and estimates a small structural model of the Australian economy with the aim of providing both a theoretically rigorous framework as well as rich enough dynamics to make the model empirically plausible. The economics of the model are simple. Households choose how much to consume and how much labour to supply. Firms choose prices and then produce enough goods to meet demand. A fraction of the domestically produced goods are exported and a fraction of the domestically consumed goods are imported, with the size of the fractions determined by the relative price of goods produced at home and abroad. This is the minimal structure needed to capture the open economy dimension of the Australian economy and it is similar to that used in many other studies, for example Lubik and Schorfheide (2005), Gali and Monacelli (2005) and Justiano and Preston (2005). In addition to this basic structure, the model is amended to account for the importance of the commodities sector for Australian exports by adding exogenous export demand and income shocks.

Estimated models derived from micro foundations have become popular tools at central banks around the world. One reason often cited for this is that structural models can be used to produce counterfactual scenarios, as well as to make predictions about how macroeconomic outcomes would change if alternative policies were implemented. Nessen (2006) provides a useful perspective on how small structural models can be used in the policy process. She argues that a model is not a tool that provides answers to questions, but rather a framework of principles in which a structured and transparent analysis can be conducted.

For any model to be a useful analytical tool, however, one first needs to establish whether or 
not it provides a reasonable description of the data. In a series of papers, Smets and Wouters (2003, 2004) show that medium scale models can fit the dynamics of a large (closed) economy well. Some recent papers have asked whether structural open economy models can provide a similarly good fit (see, for example, Justiano and Preston 2005; Fukac, Pagan and Pavlov 2006). Particularly, Justiano and Preston (2005) question whether these models can account for the influence of foreign shocks on the domestic economy. This paper shows that the influence of foreign shocks can indeed be captured by the dynamics of a small structural model and we argue that the model's success along this dimension is due to the inclusion of trade quantities in the set of time series that are used to estimate the model.

The model is estimated using Bayesian methods that exploit information from outside the data sample to generate posterior estimates of the structural parameters. The number of time series used is larger than in most other studies to ensure that the data spans the open economy dimension of the model. The magnitude of measurement errors in some of the observable time series used is also estimated. This not only allows for errors in the data introduced through the data collection process, but also recognises the fact that some of the theoretical variables of the model do not have clear-cut observable counterparts. This approach also allows something to be said about how well these time series fit the cross-equation and dynamic implications of the model.

\section{A Small Scale Model of Australia}

The structural model is in most respects a standard New Keynesian small open economy model. But the model has a number of adjustments to account for some features of the Australian economy that are peculiar compared with many other developed countries. In particular, while international trade for most developed countries appears to be driven by benefits that come from specialisation, Australia's external trade appears to be driven more by classical comparative advantage, with exports dominated by primary products, while more than half of imports are manufactured goods (see Composition of Trade 2005). In the standard model, the demand for a country's exports are determined by the level of world output and the domestic relative cost of production. Australia can be considered to be a price taker in many of its export markets and has little influence over the price of its exports. Exogenous shocks are therefore added to both the volume of export demand as well as the price that exporters receive for their goods.

Australia is also considered a small economy in the model in the sense that macroeconomic outcomes and policy in Australia are assumed to have no discernible impact on world output, inflation and interest rates. These foreign variables are thus modelled as being exogenous to Australia.

\subsection{Household Preferences}

A continuum of households populate the economy, consume goods and supply labour to firms. Consider a representative household indexed by $i \in(0,1)$ that wishes to maximise the discounted sum of its expected utility,

$E_{t}\left\{\sum_{s=0}^{\infty} \beta^{s} U\left(C_{t+s}(i), N_{t+s}(i)\right)\right\}$

where $\beta \in(0,1)$ is the household's subjective discount factor. The period utility function in consumption $C_{t}$ and labour $N_{t}$ is given by

$$
\begin{aligned}
U\left(C_{t}(i), N_{t}(i)\right)= & \exp \left(\varepsilon_{t}^{c}\right) \frac{\left(C_{t}(i) H_{t}^{-\eta}\right)^{1-\gamma}}{1-\gamma} \\
& -\frac{N_{t}(i)^{1+\varphi}}{1+\varphi}
\end{aligned}
$$

and reflects the fact that households like to consume but dislike work. $\varepsilon_{t}^{c}$ is a white noise process with variance $\sigma_{c}^{2}$. The variable $H_{t}$

$H_{t}=\int C_{t-1}(i) d i$

is a reference level of consumption capturing the notion that households not only care about their own consumption, but also care about the

\footnotetext{
(C) 2009 The University of Melbourne, Melbourne Institute of Applied Economic and Social Research
} 
lagged consumption of others. This featureoften referred to as 'external habits' or a preference for 'catching up with the Joneses'-helps to explain the inertia of aggregate output, since past levels of aggregate consumption are positively related to the marginal utility of current consumption under this set up.

\subsection{The Consumption Bundle}

Households' preferences are specified over a continuum of differentiated goods that enter the households' utility function with decreasing marginal weight. Households thus prefer to consume a mixture of differentiated goods rather than consuming just one variety. The consumption bundle $C_{t}$ is a constant elasticity of substitution (CES) aggregated index of domestically produced and imported sub-bundles $C_{t}^{d}$ and $C_{t}^{m}$

$C_{t} \equiv\left[(1-\alpha)^{\frac{1}{\delta}} C_{t}^{d \frac{\delta-1}{\delta}}+\alpha^{\frac{1}{\delta}} C_{t}^{m \frac{\delta-1}{\delta}}\right]^{\frac{\delta}{\delta-1}}$

$C_{t}^{d} \equiv\left[\int C_{t}^{d}(j)^{\frac{v-1}{v}}\right]^{\frac{v}{v-1}}$

$C_{t}^{m} \equiv\left[\int C_{t}^{m}(j)^{\frac{v-1}{v}}\right]^{\frac{v}{v-1}}$

The domestic price index (CPI) that is consistent with the specification of the utility function is then given by

$P_{t} \equiv\left[(1-\alpha) P_{t}^{d 1-\delta}+\alpha P_{t}^{m 1-\delta}\right]^{\frac{1}{1-\delta}}$

This specification implies that in steady state, domestic households spend a fraction $(1-\alpha)$ of their income on domestically produced goods.

\subsection{Import Demand}

The domestic demand for imported goods $C_{t}^{m}$ can be shown to be

$C_{t}^{m}=C_{t} \exp \left(v_{t}^{m}\right) \exp \left(\tau_{t}\right)^{-\delta}$ which depends on the relative price of imports $\tau_{t}$ as perceived by the domestic consumer

$\tau_{t}=\log \left(\frac{P_{t}^{m}}{P_{t}}\right)$

Thus, the cheaper are imported goods relative to domestic goods, the larger will be the share of imported goods in the consumption bundle. The exogenous shock to the domestic consumers demand for imported goods $v_{t}^{m}$ can be interpreted as a 'taste' shock and is assumed to follow an $\mathrm{AR}(1)$ process

$v_{t}^{m}=\rho_{m} v_{t-1}^{m}+\varepsilon_{t}^{m}$

$\varepsilon_{t}^{m} \sim N\left(0, \sigma_{m}^{2}\right)$

The exogenous taste shock $v_{t}^{m}$ absorbs variations in imports that cannot be explained by changes in relative prices, but ideally should only explain a small portion of the dynamics of imports.

\subsection{The Domestic Budget Constraint and International Financial Flows}

The representative household optimises the utility function, equation (1), subject to its flow budget constraint

$$
\begin{aligned}
B_{t+1} & +B_{t+1}^{*}+C_{t}-\frac{\psi}{2} B_{t}^{2 *}=Y_{t} \\
& +\left(\exp v_{t}^{p x}-1\right) X_{t} \\
& +R_{t} \frac{P_{t-1}}{P_{t}} B_{t}+R_{t}^{*} \frac{S_{t} P_{t-1}}{S_{t-1} P_{t}} B_{t}^{*}
\end{aligned}
$$

The variables on the left hand side are expenditure items and the terms on the right hand side are income items. $B_{t}(i)$ and $B^{* t}(i)$ are domestic and foreign bonds, respectively, where both are expressed in real domestic terms. Their respective nominal returns are $R_{t}$ and $R^{* t} . S_{t}$ is the nominal exchange rate defined such that an increase in $S_{t}$ implies a depreciation of the domestic currency. The term $\frac{\psi}{2} B_{t}^{2 *}$ is a cost paid by domestic households when they are net borrowers in the aggregate (see Benigno 2001). This ensures that the net asset position of the domestic economy is stationary and it implies 
that, ceteris paribus, a highly indebted county will have a higher equilibrium interest rate. $Y_{t}$ on the right hand side is real GDP and the term $\exp v_{t}^{p x} X_{t}$ is export income adjusted for exogenous fluctuations in the price of exports (more on this below).

Assuming a zero net supply of domestic bonds we can write the flow budget constraint as a difference equation describing the evolution of the net foreign asset position

$$
\begin{aligned}
B_{t+1}^{*}= & R_{t}^{*} \frac{S_{t} P_{t-1}}{S_{t-1} P_{t}} B_{t}^{*}-\frac{\psi}{2} B_{t}^{2^{*}} \\
& +\exp v_{t}^{p x} X_{t}-C_{t}^{m}
\end{aligned}
$$

where the change in the net foreign asset position is the difference between income received for exports and expenditure on imports plus valuation effects from inflation and changes in the nominal exchange rate and the net debtor cost $\frac{\psi}{2} B_{t}^{2^{*}}$. Households choose consumption subject to the flow budget constraint given by equation (12). Optimally allocating consumption over time yields the standard consumption Euler equation

$U_{C}\left(C_{t}\right)=\beta E_{t} R_{t} \frac{P_{t} U_{C}\left(C_{t+1}\right)}{P_{t+1}}$

where $U_{C}\left(C_{t}\right)$ is the marginal utility of consumption in period $t$. Households also choose between allocating their savings to bonds denominated in the domestic and foreign currency. Equating the marginal expected return on foreign and domestic bonds yields the uncovered interest rate parity (UIP) equilibrium condition

$R_{t}=\left(\exp \left(v_{t}^{s}\right) E_{t} \frac{R_{t}^{*}}{\psi B_{t}^{*}} \frac{S_{t}}{S_{t+1}}\right.$

where $v_{t}^{s}$ is a time varying 'risk premium' that is assumed to follow the $\operatorname{AR}(1)$ process

$v_{t}^{s}=\rho_{s} v_{t-1}^{s}+\varepsilon_{t}^{s}$

$\varepsilon_{t}^{s} \sim N\left(0, \sigma_{s}^{2}\right)$

The time varying and persistent risk premium $v_{t}^{s}$ is necessary to account for the observed deviations of the exchange rate from that implied by the UIP condition. There is no consensus in the literature on the causes of the deviations and the interpretation of the risk premium shock does not have to be literal. ${ }^{1}$

\subsection{Firms}

The domestic economy is populated by two types of firms: producers and importers. Domestic producers indexed by $j$ use labour as the sole input to manufacture differentiated goods with a linear technology

$Y_{t}(j)=\exp \left(a_{t}\right) N_{t}(j)$

where $a_{t}$ is a sector wide exogenous process that augments labour productivity assumed to follow

$v_{t}^{a}=\rho_{a} v_{t-1}^{a}+\varepsilon_{t}^{a}$

$\varepsilon_{t}^{a} \sim N\left(0, \sigma_{a}^{2}\right)$

In addition to the production sector, there is a sector that imports differentiated goods from the world and resells them domestically.

Firms have some market power over the price of the goods that they are selling since consumers prefer a mixture of differentiated goods rather than consuming just one variety. Unlike the case when all goods are perfect substitutes, this means that consumers will not switch consumption away completely from a slightly more expensive good. In this monopolistically competitive environment firms charge a markup over marginal cost.

Quantities sold in a given period are demand determined in the sense that firms are assumed to set prices in domestic currency terms and then supply the amount of goods that are demanded by consumers at that price. Both importers and domestic producers set prices according to a discrete time version of the Calvo (1983) mechanism whereby a fraction $\theta^{d}$ of firms producing domestically and a fraction $\theta^{m}$ of importing firms do not change prices in a given period. A fraction $\omega$ of both the domestic producers and importers that do change prices, use a rule of thumb that links their price 
to lagged inflation (in their own sector). This is a two-sector generalisation of Gali and Gertler (1999) that yields two Phillips curves of the following form

$\pi_{t}^{d}=\mu_{f}^{d} \pi_{t+1}^{d}+\mu_{b}^{d} \pi_{t-1}^{d}+\lambda^{d} m c_{t}^{d}+\varepsilon_{t}^{\pi}$

and

$\pi_{t}^{m}=\mu_{f}^{m} \pi_{t+1}^{m}+\mu_{b}^{m} \pi_{t-1}^{m}+\lambda^{m} m c_{t}^{m}+\varepsilon_{t}^{\pi}$

where $m c_{t}^{d}$ is the marginal cost of the domestic producers and $m c_{t}^{m}$, defined as

$m c_{t}^{m}=\log \left(\frac{S_{t} P_{t}^{*}}{P_{t}}\right)$

is the real unit cost at the dock of imported goods. The shock $\varepsilon_{t}^{\pi}$ is a cost push shock common to both sectors. The parameters in the Phillips curves are given by

$\mu_{f}^{s} \equiv \frac{\beta \theta^{s}}{\theta^{s}+\omega\left(1-\theta^{s}(1-\beta)\right)}$,

$\mu_{b}^{s} \equiv \frac{\omega}{\theta^{s}+\omega\left(1-\theta^{s}(1-\beta)\right)}$

$\lambda^{s} \equiv \frac{(1-\omega)\left(1-\theta^{s}\right)\left(1-\beta \theta^{s}\right)}{\theta^{s}+\omega\left(1-\theta^{s}(1-\beta)\right)}, \quad s \in\{d, m\}$

and domestic CPI inflation is simply the weighted average of inflation in the two sectors

$\pi_{t}=(1-\alpha) \pi_{t}^{d}+\alpha \pi_{t}^{m}$

\subsection{Export Demand}

As mentioned above, a large share of Australian exports are commodities that are traded in markets where individual countries have little market power. The standard specification of export demand is amended to reflect the fact that Australian exports and export income depend on more than just the relative cost of production in Australia and the level of world output, as would be the case in a standard open economy model. Two shocks are added to the model.
The first shock, $v_{t}^{x}$ captures variations in exports that are unrelated to the relative cost of the exported goods and the level of world output. Export volumes are then given by

$X_{t}=\left(\exp v_{t}^{x}\right)\left(\frac{P_{t}^{d}}{P_{t}^{*}}\right)^{\delta^{x}} Y_{t}^{*}$

where $Y_{t}^{*}$ is world output and $v_{t}^{x}$ is an exogenous shock that follows the $\operatorname{AR}(1)$ process

$v_{t}^{x}=\rho_{x} v_{t-1}^{x}+\varepsilon_{t}^{x}$

$\varepsilon_{t}^{x} \sim N\left(0, \sigma_{x}^{2}\right)$

We also want to allow for 'windfall' profits due to exogenous variations in the world market price of the commodities that Australia exports. We therefore add a shock to the export income equation, which in domestic real terms is given by

$Y_{t}^{x}=\left(\exp v_{t}^{p x}\right) X_{t}$

The shock $v_{t}^{p x}$ is thus a shock to real income (expressed in real domestic currency terms) received for the goods that Australia exports. It is assumed to follow the $\mathrm{AR}(1)$ process

$v_{t}^{p x}=\rho_{p x} v_{t-1}^{p x}+\varepsilon_{t}^{p x}$

$\varepsilon_{t}^{p x} \sim N\left(0, \sigma_{p x}^{2}\right)$

It is worth emphasising here the different implication of a shock to export demand, $v_{t}^{x}$, as opposed to a shock to export income, $v_{t}^{p x}$ : the former leads to higher export incomes and higher labour demand, while the latter improves the trade balance without any direct effect on the demand for labour by the exporting industry.

\subsection{The World Economy}

The log of world output, inflation and interest rates, denoted $\left\{y_{t}^{*}, \pi_{t}^{*}, i_{t}^{*}\right\}$, are assumed to follow an unrestricted vector autoregression

$\left[\begin{array}{c}y_{t}^{*} \\ \pi_{t}^{*} \\ i_{t}^{*}\end{array}\right]=M\left[\begin{array}{c}y_{t-1}^{*} \\ \pi_{t-1}^{*} \\ i_{t-1}^{*}\end{array}\right]+\varepsilon_{t}^{*}$ 
The rest of the world is assumed to be unaffected by the Australian economy and the coefficients in $M$ and the covariance matrix of the world shock vector $\varepsilon_{t}^{*}$ can therefore be estimated separately from the rest of the model.

\subsection{Monetary Policy}

A simple way to represent monetary policy that has been found to empirically fit central bank behaviour quite well is to let the short interest rate follow a variant of the Taylor rule, letting the interest rate be determined by a reaction function of lagged inflation, lagged output and the lagged interest rate:

$i_{t}=\phi_{y} y_{t-1}+\phi_{\pi} \pi_{t-1}+\varepsilon_{t}^{i}$

where $\varepsilon_{t}^{i}$ is a transitory deviation from the rule with variance $\sigma_{i}^{2}$. This completes the description of the structural model. ${ }^{2}$

\section{Estimation Strategy}

The parameters of the model are estimated using Bayesian methods that combine prior information and information that can be extracted from aggregate data series. An and Schorfheide (2007) provide an overview of the methodology. Conceptually, the estimation works in the following way. Denote the vector of parameters to be estimated $\Theta \equiv\{\gamma, \eta, \varphi \ldots\}$ and the $\log$ of the prior probability of observing a given vector of parameters $L(\Theta)$. The function $L(\Theta)$ summarises what is known about the parameters prior to estimation. The log likelihood of observing the data set $Z$ for a given parameter vector $\Theta$ is denoted $L(Z \mid \Theta)$. The posterior estimate $\hat{\Theta}$ of the parameter vector is then found by combining the prior information with the information in the estimation sample. In practise, this is done by numerically maximising the sum of the two over $\Theta$, so that $\hat{\Theta}=\arg \max (L(\Theta)+L(Z \mid \Theta))$

The first step of the estimation process is to specify the prior probability over the parameters $\Theta$. Prior information can take different forms. For instance, for some parameters economic theory determines the sign. For other parameters we may have independent survey data, as is the case for the frequency of price changes, for example (see Bils and Klenow 2004; Alvarez et al. 2005). Priors can also be based on similar studies where data for other countries were used. The restrictions implied by the theoretical model means that prior information about a particular parameter can also be useful for identifying other parameters more sharply. For instance, it is typically difficult to separately identify the degree of price stickiness $\theta$ and the curvature of the disutility of supplying labour $\gamma$ just by using information from aggregate time series. However, a combination of the two variables may have strong implications for the likelihood function (that is, there may be a 'ridge' in the likelihood surface). Survey evidence suggests that the average frequency of price changes is somewhere between five and 13 months. By choosing a prior probability for the range of the stickiness parameter $\theta$ that reflects this information, we may also identify $\gamma$ more sharply.

Unfortunately, we do not have independent information about all of the parameters of the model. A cautious strategy when hard priors are difficult to find is to use diffuse priors, that is, to use prior distributions with wide dispersions. If the data is informative, the dispersion of the posterior should be smaller than that of the prior. However, Fukac, Pagan and Pavlov (2006) point out that using informative priors, even with wide dispersions can affect the posteriors in non-obvious ways.

Arguably, hard prior information exists for the discount factor $\beta$, the steady-state share of imports/exports in GDP a and the average duration of good prices $\theta^{d}$ and $\theta^{m}$. The first two can be deduced from the average real interest rate and the average share of imports and exports of GDP and are calibrated as $\{\beta, \alpha\}=\{0.99,0.18\}$. Calibration can be viewed as a very tight prior. The price stickiness parameters $\theta^{d}$ and $\theta^{m}$ are assigned priors that are centred around the mean duration found in European data (see Alvarez et al. 2005).

The prior distributions of the variances of the exogenous shocks are truncated uniform over the interval $[0, \infty)$. It is common to use more restrictive priors for the exogenous shocks, as for 
example in Smets and Wouters (2003), Lubik and Schorfheide (forthcoming), Justiano and Preston (2005) and Kam, Lees and Liu (2006), but since most shocks are defined by the particular model used, it is unclear what the source of the prior information would be.

The priors of the variances of the measurement error parameters are uniform distributions on the interval $\left[0, \sigma_{Z n}^{2}\right.$ ) where $\sigma_{Z n}^{2}$ is the variance of the corresponding time series. Economic theory dictates the domains of the rest of the priors, but we have little information about their modes and dispersions. These priors are therefore assigned wide dispersions. Information about the prior distributions for the individual parameters is given in Table 1.

\subsection{Mapping the Model into Observable Time Series}

The model of Section 2 is solved by first taking linear approximations of the structural equations around the steady state and then finding the rational expectations equilibrium law of motion. The linearised equations are listed in the Appendix and the Soderlind (1999) algorithm was used to solve the model. The solution can be written in $\operatorname{VAR}(1)$ form

$X_{t}=A X_{t-1}+C \varepsilon_{t}$

where $X_{t}$ is a vector containing the variables of the model and the coefficient matrices $A$ and $C$ are functions of the structural parameters $\Theta$.

Table 1 Prior and Posterior Distributions of Parameters

\begin{tabular}{|c|c|c|c|c|c|}
\hline \multirow[b]{2}{*}{ Parameter } & \multicolumn{3}{|c|}{ Prior distribution } & \multicolumn{2}{|c|}{ Posterior distribution } \\
\hline & Type & Mode & Standard deviation & Mode & Standard deviation \\
\hline \multicolumn{6}{|c|}{ Households and firms } \\
\hline$\gamma$ & normal & 3 & 0.44 & 2.97 & 0.30 \\
\hline$\eta$ & normal & 2 & 0.66 & 1.48 & 0.13 \\
\hline$\varphi$ & normal & 2 & 0.44 & 1.35 & 0.31 \\
\hline$\omega$ & Beta & 0.3 & 0.10 & 0.24 & 0.08 \\
\hline$\delta$ & normal & 1 & 0.10 & 0.86 & 0.09 \\
\hline$\delta^{x}$ & normal & 1 & 0.10 & 0.15 & 0.06 \\
\hline$\theta$ & beta & 0.75 & 0.04 & 0.89 & 0.01 \\
\hline$\theta^{m}$ & beta & 0.75 & 0.04 & 0.90 & 0.01 \\
\hline$\psi$ & normal & 0.01 & 0.02 & 0.07 & 0.02 \\
\hline \multicolumn{6}{|l|}{ Taylor rule } \\
\hline$\phi_{y}$ & normal & 0.5 & 0.25 & 0.02 & 0.01 \\
\hline$\phi_{\pi}$ & normal & 1.5 & 0.29 & 0.41 & 0.04 \\
\hline$\phi_{i}$ & beta & 0.5 & 0.25 & 0.87 & 0.03 \\
\hline \multicolumn{6}{|c|}{ Exogenous persistence } \\
\hline$\rho_{a}$ & beta & 0.5 & 0.28 & 0.71 & 0.05 \\
\hline$\rho_{s}$ & beta & 0.5 & 0.28 & 0.81 & 0.08 \\
\hline$\rho_{p x}$ & beta & 0.5 & 0.28 & 0.81 & 0.05 \\
\hline$\rho_{x}$ & beta & 0.5 & 0.28 & 0.90 & 0.07 \\
\hline$\rho_{m}$ & beta & 0.5 & 0.28 & 0.80 & 0.05 \\
\hline$\sigma_{a}^{2}$ & uniform & {$[0, \infty)$} & & $9.13 \times 10^{-5}$ & $2.30 \times 10^{-5}$ \\
\hline$\sigma_{s}^{a}$ & uniform & {$[0, \infty)$} & & $2.02 \times 10^{-3}$ & $2.59 \times 10^{-3}$ \\
\hline$\sigma_{c}^{s}$ & uniform & {$[0, \infty)$} & & $1.79 \times 10^{-5}$ & $5.81 \times 10^{-6}$ \\
\hline$\sigma_{\pi}^{2}$ & uniform & {$[0, \infty)$} & & $2.70 \times 10^{-5}$ & $6.92 \times 10^{-5}$ \\
\hline$\sigma_{p x}^{2}$ & uniform & {$[0, \infty)$} & & $6.82 \times 10^{-5}$ & $3.39 \times 10^{-5}$ \\
\hline$\sigma_{x}^{2 x}$ & uniform & {$[0, \infty)$} & & $4.89 \times 10^{-5}$ & $8.84 \times 10^{-5}$ \\
\hline$\sigma_{m}^{x}$ & uniform & {$[0, \infty)$} & & $2.12 \times 10^{-5}$ & $5.51 \times 10^{-6}$ \\
\hline$\sigma_{i}^{m}$ & uniform & {$[0, \infty)$} & & $7.58 \times 10^{-7}$ & $1.86 \times 10^{-7}$ \\
\hline
\end{tabular}

${ }^{C} 2009$ The University of Melbourne, Melbourne Institute of Applied Economic and Social Research 
equation (33) is called the transition equation. The next step is to decide which (combinations) of the variables in $X_{t}$ are observable. The mapping from the transition equation to observable time series are determined by the measurement equation

$Z_{t}=D X_{t}+e_{t}$

The selector matrix $D$ maps the theoretical variables in the state vector $X_{t}$ into a vector of observable variables $Z_{t}$. The term $e_{t}$ is a vector of measurement errors. For theoretical variables that have clear counterparts in observable time series, the measurement errors capture noise in the data collecting process. The measurement errors may also capture discrepancies between the theoretical concepts of the model and observable time series. For instance, GDP, non-farm GDP and market sector GDP all measure output, but none of these measures corresponds exactly to the model's variable $y_{t}$. The measure of total GDP includes farm output, which varies due to factors other than technology and labour inputs, most notably the weather. One may therefore want to exclude farm products. But in the model, more abundant farm goods will lead to higher overall consumption and lower marginal utility and perhaps also higher exports, so excluding it altogether is also not appropriate. Total GDP also includes government expenditure which is not determined by the utility maximising agents of the model, but it will affect the aggregate demand for labour and therefore market wages. The state space system, that is, the transition equation (33) and the measurement equation (34), is quite flexible and can incorporate all three measures of GDP, allowing the data to determine how well each of them correspond to the model's concept of output. This multiple indicator approach was proposed by Boivin and Giannoni (2005) who argue that not only does this allow us to be agnostic about which data to use, but by using a larger information set it may also improve estimation precision.

Some, but not all, of the observable time series are assumed to contain measurement errors and the magnitude of these are estimated together with the rest of the parameters. Counting both measurement errors and the exogenous shocks, the total number of shocks in the model is more than is necessary to avoid stochastic singularity. That is, the total number of shocks is larger than the total number of observable variables in $Z_{t}$. It is reasonable to ask whether or not all of the shocks can be identified and the answer is that it depends on the actual data generating process. The measurement errors are white noise processes specific to the relevant time series that are uncorrelated with other indicators as well as with their own leads and lags. To the extent that the cross-equation and dynamic implications that distinguish the structural shocks from the measurement errors of the model are also present as observable correlations in the time series, it will be possible to identify the structural shocks and the measurement errors separately. Incorrectly excluding the possibility of measurement errors may bias the estimates of the parameters governing both the persistence and variances of the structural shocks. Also, by estimating the magnitude of the measurement errors we can get an idea of how well different data series match the corresponding model concept.

\subsection{Computing the Likelihood}

The linearised model, equation (33), and the measurement, equation (34), can be used to compute the covariance matrix of the theoretical, one step ahead forecast errors implied by a given parameterisation of the model. That is, without looking at any data, we can compute what the covariance of our errors would be if the model was the true data generating process and we used the model to forecast the observable variables. This measure, denoted $\Omega$, is a function of both the assumed functional forms and the parameters and is given by

$\Omega=D P D^{\prime}+E e_{t} e_{t}^{\prime}$

where $P$ is the covariance matrix of the one period ahead forecast errors of the state

$$
\begin{aligned}
P= & A\left(P-P D^{\prime}\left(D P D^{\prime}+E e_{t} e_{t}^{\prime}\right)^{-1} D P A^{\prime}\right) \\
& +C E \varepsilon_{t} \varepsilon_{t}^{\prime} C^{\prime}
\end{aligned}
$$

\footnotetext{
(ㄷ) 2009 The University of Melbourne, Melbourne Institute of Applied Economic and Social Research
} 
The covariance of the theoretical forecast errors $\Omega$ is used to evaluate the likelihood of observing the time series in the sample, given a particular parameterisation of the model. Formally, the $\log$ likelihood of observing $Z$ given the parameter vector $\Theta$ is

$$
\begin{aligned}
L(Z \mid \Theta)= & -.5 \sum_{t=0}^{T}[p \ln (2 \pi)+\ln |\Omega| \\
& \left.+u_{t}^{\prime} \Omega^{-1} u_{t}\right]
\end{aligned}
$$

where $p \times T$ are the dimensions of the observable time series $Z$ and $u t$ is a vector of the actual one step ahead forecast errors from predicting the variables in the sample $Z$ using the model parameterised by $\Theta$. The actual (sample) one step ahead forecast errors can be computed from the innovation representation

$\hat{X}_{t+1}=A \hat{X}_{t}+K u_{t}$

$u_{t}=Z_{t}-D \hat{X}_{t}$

where $K$ is the Kalman gain

$K=A P D^{\prime}\left(D P D^{\prime}+E e_{t} e_{t}^{\prime}\right)^{-1}$

The method is described in detail in Hansen and Sargent (2005).

To help understand the log likelihood function intuitively, consider the case of only one observable variable so that both $\Omega$ and $u_{t}$ are scalars. The last term in the log likelihood function, equation (37) can then be written as $u_{t}^{2} / \Omega$ so for a given squared error $u_{t}^{2}$ the $\log$ likelihood increases in the variance of the model's forecast error variance. This term will thus make us choose parameters in $\Theta$ that make the forecast errors of the model large since a given error is more likely to have come from a parameterisation that predicts large forecast errors. The determinant term $\ln |\Omega|$ (the determinant of a scalar is simply the scalar itself) counters this effect; to maximise the complete likelihood function we need to find the parameter vector $\Theta$ that yields the optimal trade-off between choosing a model that can explain our actual forecast errors $u_{t}$ while not making the implied theoretical forecast errors too large.
Another way to understand the likelihood function is to recognise that there are (roughly speaking) two sources contributing to the forecast errors $u_{t}$, namely shocks and incorrect parameters. The set of parameters $\Theta$ that maximises the log likelihood function, equation (37), are those that reduce the forecast errors caused by incorrect parameters as much as possible by matching the theoretical forecast error variance $\Omega$ with the sample forecast error covariance $E u_{t} u_{t}^{\prime}$, thereby attributing all remaining forecast errors to shocks.

\subsection{The Data}

The data sample is from 1991:Q1 to 2006:Q2 where the first eight observations are used as a convergence sample for the Kalman filter. 13 time series were used as indicators for the theoretical variables of the model, which is more than that of most other studies estimating structural small open economy models. Lubik and Schorfheide (2007) estimate a small open economy model on data for Canada, the United Kingdom, New Zealand and Australia using terms of trade as the only observable variable relating to the open economy dimension of the model. Similarly, in Justiano and Preston (2005) the real exchange rate between the United States and Canada is the only data series relating to the open economy dimension of the model. Neither of these studies use trade volumes to estimate their models. This is also true for Kam, Lees and Liu (2006), though this study uses data on imported goods prices rather than only aggregate CPI inflation.

In this paper, data for the rest of the world is based on trade weighted G7 output and inflation and an (unweighted) average of US, Japanese and German/euro interest rates. ${ }^{3}$ Three domestic indicators that are assumed to correspond exactly to their respective model concepts are the cash rate, the nominal exchange rate and trimmed mean quarterly CPI inflation. The rest of the domestic indicators are assumed to contain measurement errors. These are GDP, non-farm GDP, market sector GDP, exports as share of GDP, the terms of trade (defined as the price of exports over the price of imports) and labour productivity. 
Table 2 Relative Magnitude of Measurement Errors

\begin{tabular}{lcc}
\hline Data & Model & $\Sigma_{e \mathrm{e}} / \Sigma_{z \mathrm{z}}$ \\
\hline Interest rate & $i_{t}$ & - \\
Nominal exchange rate change & $\Delta s_{t}$ & - \\
CPI trimmed mean inflation & $\pi_{t}$ & - \\
Real GDP & $y_{t}$ & 0.03 \\
Real non-farm GDP & $y_{t}$ & 0.05 \\
Real market sector GDP & $y_{t}$ & 0.16 \\
Export share of GDP & $x_{t}-y_{t}$ & 0.00 \\
Import share of GDP & $c_{t}^{m}-y_{t}$ & 0.00 \\
Terms of trade & $v_{t}^{p x}-m c_{t}^{m}$ & 0.60 \\
Labour productivity & $a_{t}$ & 0.00 \\
\hline
\end{tabular}

All real variables are linearly detrended and inflation and interest rates were demeaned. The correspondence between the data series and the model concepts are described in Table 2.

\section{Estimation Results}

Table 1 reports the mode and standard deviation of the prior and posterior distributions of the structural parameters of the model. The posterior modes were found using Bill Goffe's simulated annealing algorithm. The posterior distribution was generated by the Random-Walk Metropolis Hastings algorithm using 2 million draws, where the starting value for the parameter vector is the mode of the posterior as estimated by the simulated annealing algorithm and the first 100000 draws are used as a burn-in sample.

Ideally, the posterior distributions should have a smaller variance than the prior distribution since this would indicate that the data is informative about the parameters. For most of the parameters this is the case. Imports seem to be more price elastic than exports, as evidenced by the significantly larger estimated value of $\delta$ as compared to $\delta^{x}$. The estimated frequency of price changes in the imported goods sector is lower than that estimated for prices in the domestically produced goods sector.

The parameters in the Taylor rule suggest that policy responses to inflation and output are very gradual, with a high estimated value for the parameter on the lagged interest rate. The response of the short interest rate to output deviations is quite small, with the short interest rate appearing to respond mostly to inflation.

\subsection{Model Fit}

The in-sample fit of the model can be assessed by plotting the one period ahead forecasts against the actual observed indicators (see Figure 1).

The model provides a very good in-sample description of the dynamics of the cash rate, which is likely to be primarily because its persistence makes it easy to predict. The model is also able to fit most of the other time series reasonably well, with the exception of the nominal exchange rate and the terms of trade.

The variances of the errors in the measurement, equation (34), are estimated jointly with the structural parameters of the model. These variances capture series specific transitory shocks to the observable time series. A low estimated measurement error variance indicates that the associated observable time series matches the corresponding model concept closely. The ratios of the measurement errors over the variance of the corresponding time series are reported in Table 2 .

The variance ratios for the various measures of GDP are particularly interesting, since we used multiple indicators for this variable. The estimated value of these ratios indicate that real GDP appears to conform slightly better to the dynamic and cross-equation implications of the model than real non-farm GDP, but the difference is small. The third indicator for output, domestic market sector GDP appears to provide the poorest fit.

The terms of trade stands out as the time series that the model has the biggest problem fitting; more than half of the variance of the terms of trade is estimated to be due to measurement errors.

\subsection{The Open Economy Dimension of the Model}

Table 3 below reports the variance decomposition $^{4}$ of the model evaluated at the estimated posterior mode reported in Table 1 . The first row contains the fraction of the variances that originate from outside Australia. Foreign shocks explain 27 per cent, 21 per cent and 22 per cent respectively of the variance of

\footnotetext{
(C) 2009 The University of Melbourne, Melbourne Institute of Applied Economic and Social Research
} 
Figure 1 Actual Data and Model's One Step Ahead Predictions
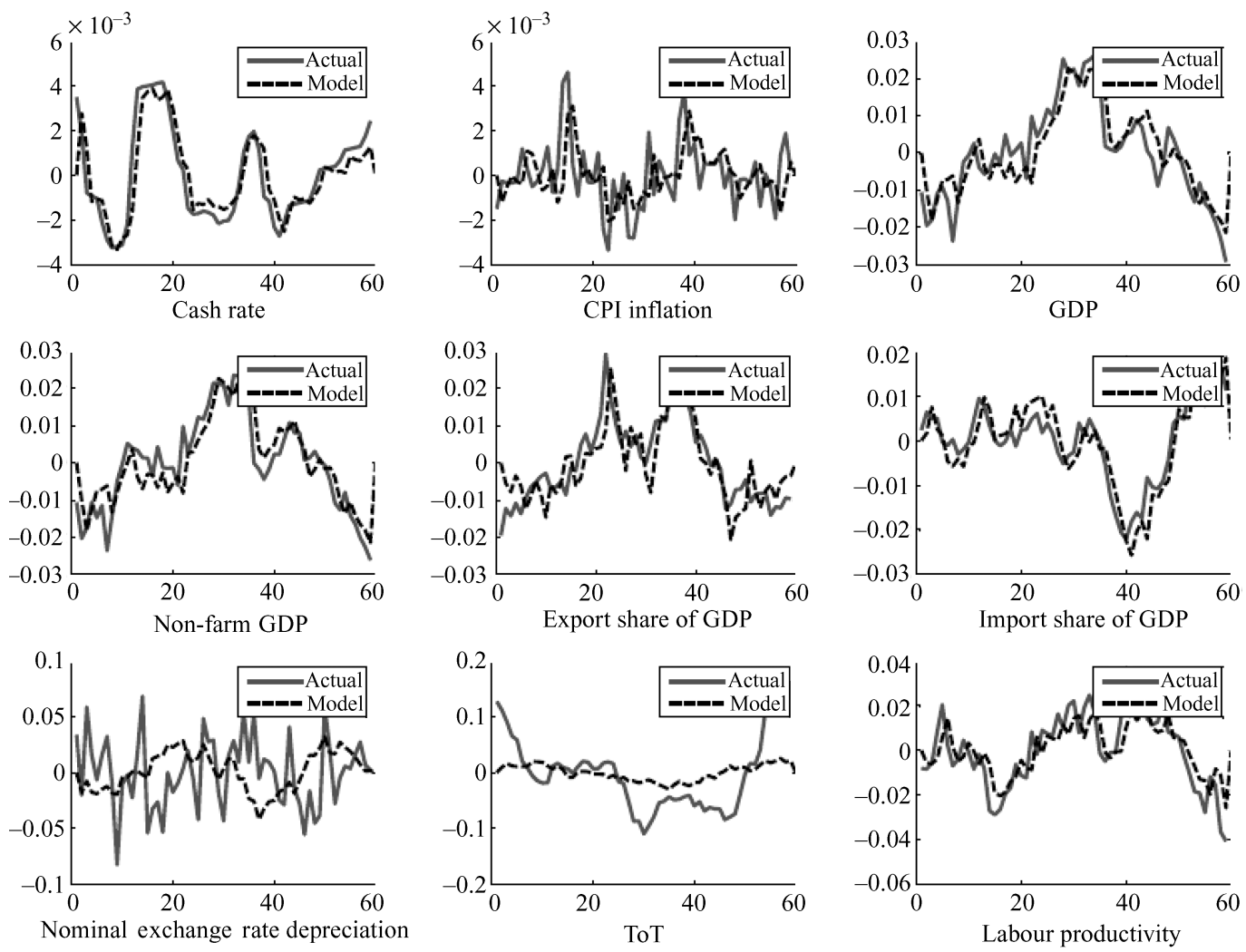

Table 3 Variance Decomposition

\begin{tabular}{lccccc}
\hline & Output & Inflation & Exports & $\Delta$ Exchange rate & Interest rate \\
Shock/variable & $\mathrm{y}$ & $\pi$ & $\mathrm{x}$ & $\Delta \mathrm{s}$ & $\mathrm{i}$ \\
\hline Foreign & 0.27 & 0.21 & 0.45 & 0.19 & 0.22 \\
& $(0.11-0.46)$ & $(0.10-0.37)$ & $(0.26-0.59)$ & $(0.10-0.22)$ & $(0.08-0.41)$ \\
Productivity & 0.00 & 0.07 & 0.00 & 0.01 & 0.01 \\
& $(0-0.2)$ & $(0.02-0.16)$ & $(0-0.02)$ & $(0-0.01)$ & $(0-0.02)$ \\
UIP & 0.06 & 0.04 & 0.06 & 0.56 & 0.05 \\
& $(0.01-0.18)$ & $(0.01-0.14)$ & $(0.02-0.23)$ & $(0.44-0.69)$ & $(0.01-0.12)$ \\
Demand & 0.16 & 0 & 0.02 & 0.01 & 0.05 \\
& $(0.04-0.27)$ & $(0-0.01)$ & $(0.01-0.05)$ & $(0.01-0.01)$ & $(0.01-0.15)$ \\
Cost push & 0.02 & 0.19 & 0 & 0.02 & 0.03 \\
& $(0-0.14)$ & $(0.06-0.34)$ & $(0-0.02)$ & $(0-0.15)$ & $(0-0.11)$ \\
Export demand & 0.08 & 0.09 & 0.12 & 0.08 & 0.06 \\
& $(0.02-0.16)$ & $(0.03-0.17)$ & $(0.05-0.22)$ & $(0.03-0.13)$ & $(0.01-0.13)$ \\
Export price & 0.23 & 0.34 & 0.27 & 0.11 & 0.25 \\
Import demand & $(0.09-0.48)$ & $(0.14-0.67)$ & $(0.11-0.51)$ & $(0.06-0.25)$ & $(0.05-0.60)$ \\
Taylor rule & 0.03 & 0.03 & 0.06 & 0.02 & 0.02 \\
& $(0.01-0.05)$ & $(0.01-0.07)$ & $(0.03-0.09)$ & $(0.01-0.04)$ & $(0.01-0.06)$ \\
& 0.15 & 0 & 0.02 & 0.01 & 0.31 \\
& $(0.03-0.29)$ & $(0-0.02)$ & $(0.01-0.06)$ & $(0.01-0.03)$ & $(0.11-0.56)$ \\
\hline
\end{tabular}

Note: Figures in brackets indicate $95 \%$ posterior probability intervals. 
Figure 2 Impulse Responses to Monetary Policy Shock
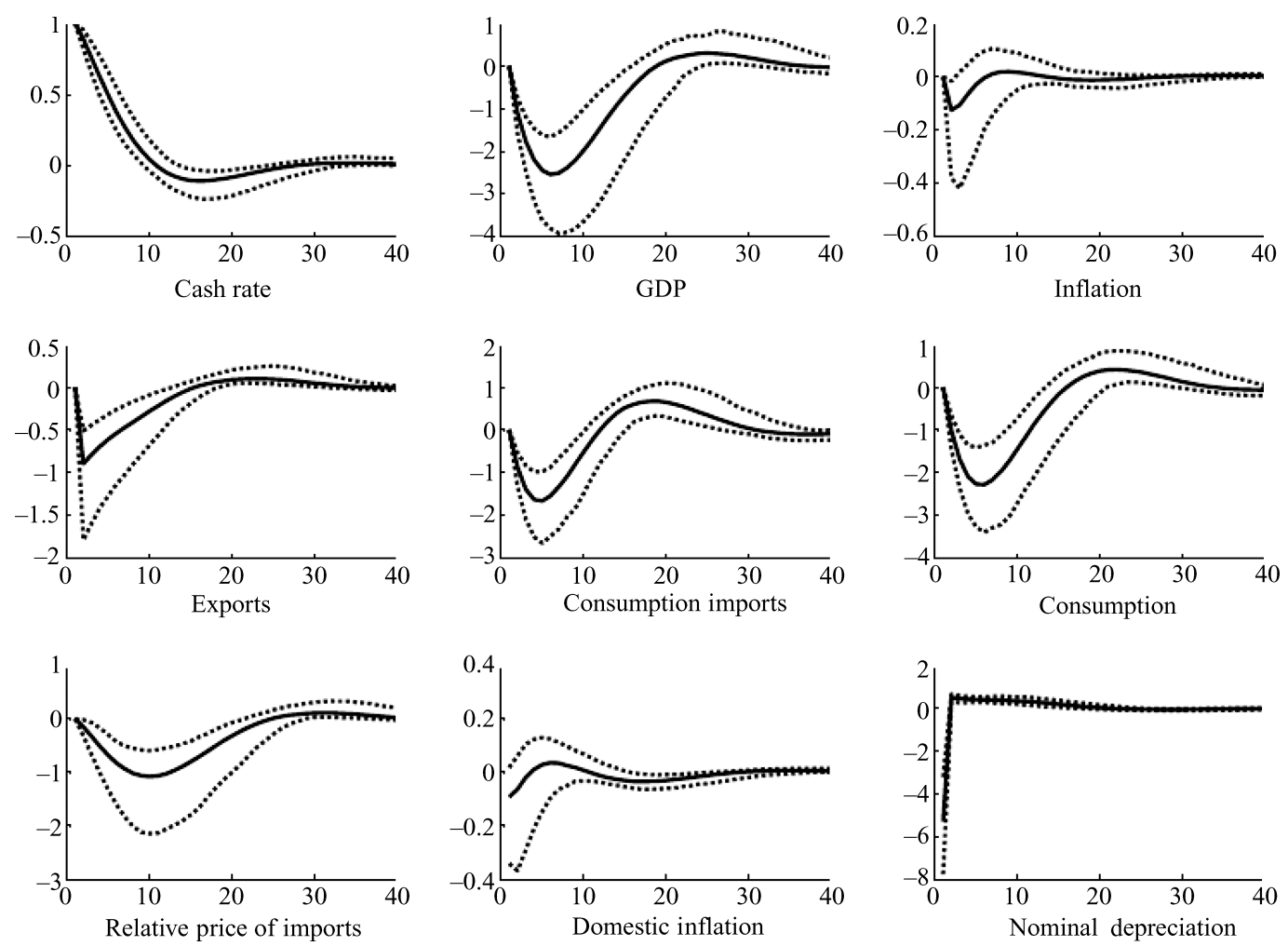

domestic output, inflation and interest rates. This can be compared to what is suggested by an unrestricted VAR(4) in world and domestic output, inflation and interest rates (with the world variables assumed to be exogenous to the domestic variables). Such estimates suggest that foreign shocks are responsible for 49 per cent, 32 per cent and 45 per cent of the domestic variance of output, inflation and interest rates, respectively. The structural model parameterised at the posterior mode thus attributes somewhat less of the variance of domestic variables to foreign shocks than the unrestricted VAR regressions; although for inflation, it is spanned by the 95 per cent probability interval.

The fact that the model is close to matching the evidence of the influence of foreign shocks on the Australian economy from a less restricted model is reassuring, but at odds with some previous studies. Justiano and Preston (2005), estimate a seemingly unrelated regression model on Canadian and US data and find that a sizeable fraction of domestic volatility does indeed originate abroad. However, their structural model, which is similar to the one presented here, attributes less than 1 per cent to foreign sources. They interpret this as a failure of their structural model to capture the open economy aspects of the data, in spite of its ability to replicate the cross correlations and dynamics of the Canadian variables.

Apart from the fact that the models are estimated using data for different countries, what can explain this difference in results? One reason may be that Justiano and Preston let the United States proxy for the world economy while in this paper the rest of the world is represented by trade weighted data on a larger set of countries. Any shock that emanates from outside the United States, for instance from Europe, will be attributed to the United States in their reduced form exercise, but it is not clear that a European shock will be appropriately captured by the bilateral US-Canada data. 
Figure 3 Impulse Responses to Export Demand Shock
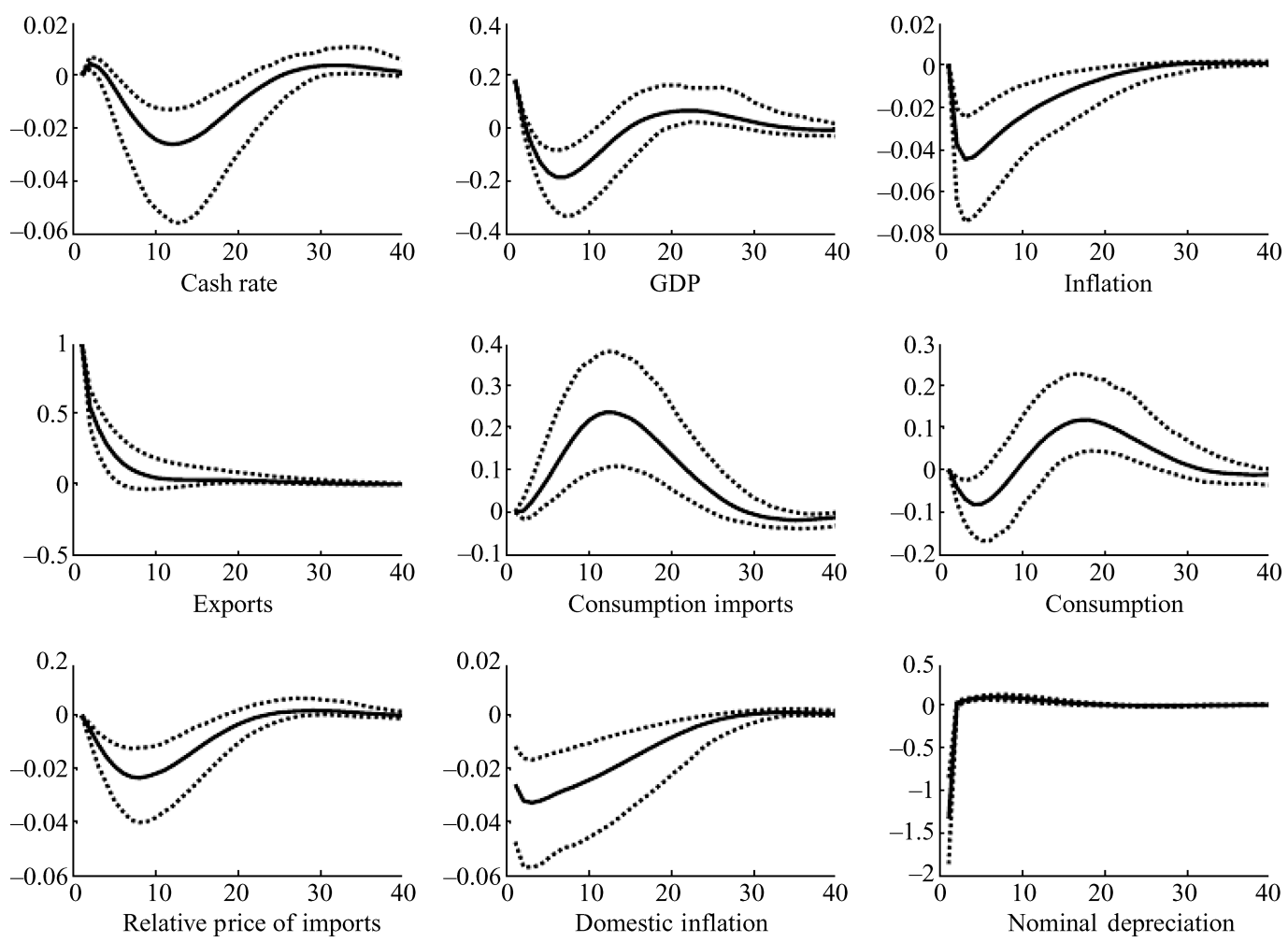

Another reason why the present model may better capture the impact of foreign shocks is that it is estimated using data on trade volumes. Not using data on imports and exports makes it harder for any model to distinguish between domestic demand shocks and demand for the domestically produced goods coming from abroad.

These results are not significantly affected by the inclusion of measurement errors in some of the time series. The fraction of domestic variance attributed to foreign shocks (evaluated at the mode) increases somewhat, but the 95 per cent probability intervals hardly change at all. ${ }^{5}$

\subsection{The Impact of a Monetary Policy Shock}

Figure 2 displays the impulse responses to a unit shock to the (annualised) cash rate for selected endogenous variables together with the 95 per cent probability intervals.
Evaluated at the mode, an unanticipated increase in interest rates of one percentage point leads to a fall in output with the maximum negative response of 2.5 percentage points occurring after six quarters. There are two factors contributing to the fall in output. First, the higher real interest rate leads to a fall in domestic consumption. Second, the higher return on domestic bonds leads to a higher demand for the domestic currency denominated assets, leading to a currency appreciation. Lower domestic consumption and less demand for labour both reduce the market real wage, causing a fall in inflation. This is reinforced by the appreciating exchange rate which makes imports cheaper and further decreases inflation. (However, initially consumer prices of imported goods do not fall as much as domestically produced goods which makes imported goods initially relatively more expensive.) The peak response of (annualised) inflation to the unit shock to the interest rate is a 
Figure 4 Impulse Responses to Export Income Shock
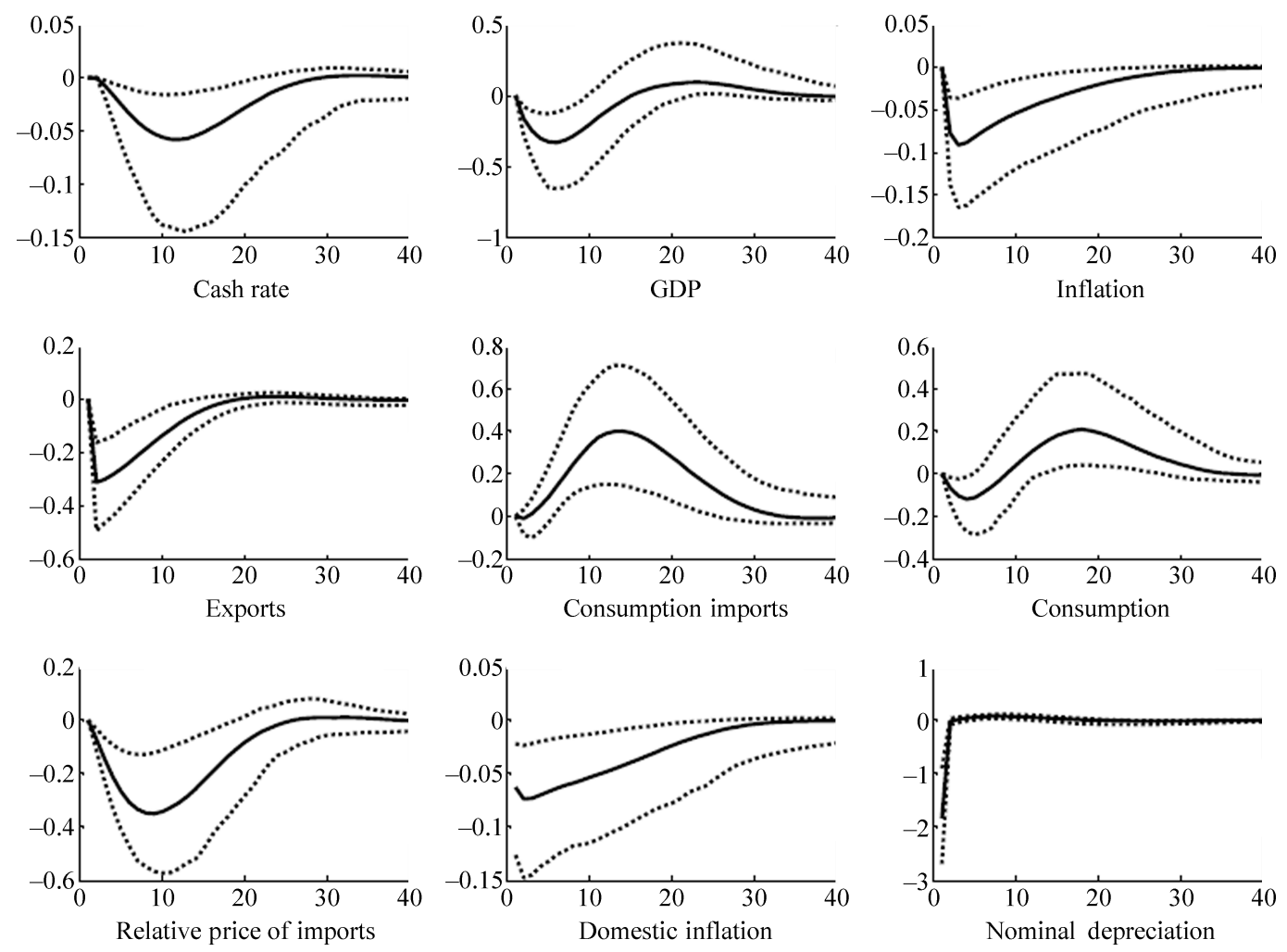

fall of approximately 0.15 percentage points two quarters after impact. The estimated maximum response of inflation to a monetary policy shock is faster than that which is found in some other studies, including those employing structural VARs (see, for instance, Dungey and Pagan 2000; Berkelmans 2005). Some of this difference may be explained by the relatively stringent restrictions imposed by the structural model compared with an SVAR. Another factor that could contribute to the relatively rapid response to a monetary policy shock in the present model may be that the sample used does not include the change to an inflation targeting regime in the early 1990s. If the credibility of the new monetary policy regime was established only gradually, then this could contribute to a relatively slow estimated responses of inflation and output to an increase in the cash rate for studies that incorporate this transitory period.

\subsection{The Impact of Export Demand and Income Shocks}

The effects of an exogenous increase in the demand for Australian exports are illustrated in Figure 3. A one percentage point increase in export demand leads on impact to a 0.2 percentage point increase in GDP (consistent with the share of the export sector in GDP). It also leads to an appreciation of the exchange rate and boosts imports. The appreciating exchange rate leads to a fall in inflation, though it is quantitatively small (less than 0.03 percentage points at the maximum impact). These effects can be contrasted with the estimated response to a positive shock to the export price. Remember, the main difference between the export price and demand shock is that a price shock does not put direct pressure on the domestic labour market. Figure 4 shows that an income shock, like a demand shock, leads to an appreciation of the

\footnotetext{
(ㄷ) 2009 The University of Melbourne, Melbourne Institute of Applied Economic and Social Research
} 
Figure 5 Impulse Responses to Productivity Shock
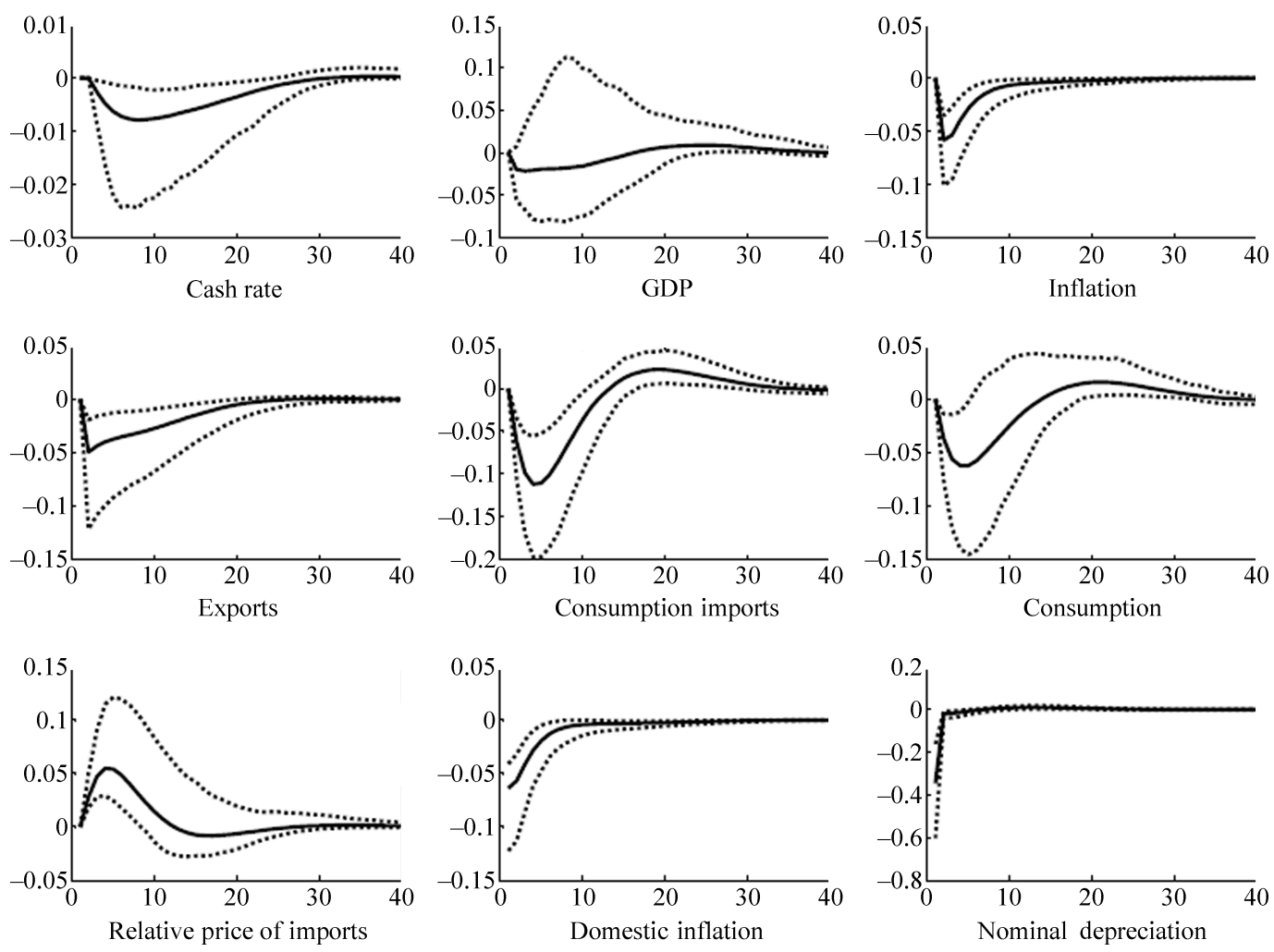

exchange rate. The response of the endogenous variables are very similar, with the exception of the volume of exports, which falls due to the appreciating exchange rate. Due to the low elasticity of export demand, the quantitative effect is small.

\subsection{The Impact of a Productivity Shock}

Figure 5 plots the impulse responses to a unit shock to Australian productivity. As expected, inflation falls and the nominal exchange rate appreciates. A less obvious effect is that the consumption of imported goods falls in spite of the appreciating exchange rate. This is because domestic goods prices fall sufficiently so as to make imports relatively more expensive. The effect of overall GDP growth is ambiguous.

\section{Conclusion}

This paper presents a small structural model of the Australian economy estimated using
Bayesian techniques and based on a standard New Keynesian small open economy specification similar to that used by numerous other studies. However, there are four aspects in which the estimation of the model deviates from previous studies.

The first is that the export demand and export income equations are amended with exogenous shocks to control for the prominent role played by commodities in the Australian export sector. When the model is estimated, the export demand shock appears to play a larger role than the export income shock in explaining the variance of domestic variables.

Second, a larger number of time series were used to estimate the model. In particular, data on import and export volumes were used in addition to the standard aggregate variables to ensure that the data spans the open economy dimension of the model.

Third, flat prior distributions were used for the variances of the structural shocks. This reflects the fact that most of the structural shocks 
are defined jointly by the model and the data with little or no role for economic theory nor independent sources of information to help determine the magnitude of these shocks.

Fourth, the magnitude of measurement errors in some of the time series was estimated together with the structural parameters of the model. This acknowledges the fact that not only is error sometimes introduced through the data collection process, but also that the model variables do not always have clear cut counterparts in observable time series.

The estimated model provides a good fit for most of the observable variables and appears to be able to capture the open economy dimensions of the data reasonably well. The model produces estimates that are close to those from studies using unrestricted VARs on the importance of foreign shocks to the domestic variance of output, inflation and interest rates. Given the simplicity of the model, this result holds promise for the usefulness of these types of open economy models as analytical tools. However, there are other dimensions in which the model performs less well. Particularly, movements in the terms of trade are not well captured by the model and the reasons for this should be a subject of future investigation.

First version received September 2007; final version accepted July 2008 (Eds).

\section{Appendix 1: The Linearised Model}

The consumption Euler Equation

$$
\begin{aligned}
c_{t}= & \frac{\gamma}{\gamma-\eta-\gamma \eta} E_{t} c_{t+1}+\frac{-\eta(1-\gamma)}{\gamma-\eta-\gamma \eta} c_{t-1} \\
& -\frac{1}{\gamma-\eta-\gamma \eta}\left(i_{t}-E_{t} \pi_{t+1}\right)+\varepsilon_{t}^{c}
\end{aligned}
$$

Import demand

$c_{t}^{m}=c_{t}-\delta \tau_{t}+v_{t}^{m}$

Domestic consumption demand

$c_{t}^{d}=c_{t}+\delta \tau_{t}$
The relative price of imported goods for the domestic consumer

$\tau_{t}=\tau_{t-1}+\pi_{t}^{m}-\pi_{t}$

Export demand

$x_{t}=-\delta^{x} \tau_{t}^{*}+Y_{t}^{*}+v_{t}^{x}$

The relative price of goods produced domestically sold to the world

$\tau_{t}^{*}=\tau_{t-1}^{*}+\pi_{t}-\pi_{t}^{*}-\Delta s_{t}$

Domestic production (resource constraint)

$y_{t}=(1-\alpha) c_{t}^{d}+\alpha x_{t}$

where total production is given by

$y_{t}=n_{t}+a_{t}$

where

$a_{t}=\rho_{a} a_{t-1}+\varepsilon_{t}^{a}$

Inflation of domestically produced goods

$\pi_{t}^{d}=\mu_{f}^{d} \pi_{t+1}^{d}+\mu_{b}^{d} \pi_{t-1}^{d}+\lambda^{d} m c_{t}^{d}+\varepsilon_{t}^{\pi}$

Inflation of imported goods

$\pi_{t}^{m}=\mu_{f}^{m} \pi_{t+1}^{m}+\mu_{b}^{m} \pi_{t-1}^{m}+\lambda^{m} m c_{t}^{m}+\varepsilon_{t}^{\pi}$

CPI inflation

$\pi_{t}=(1-\alpha) \pi_{t}^{d}+\alpha \pi_{t}^{m}$

Uncovered interest rate parity condition

$i_{t}-i_{t}^{*}=\Delta E_{t} s_{t+1}-\psi b_{t}^{*}+v_{t}^{*}$

Flow budget constraint

$b_{t+1}^{*}=b_{t}^{*}+x_{t}-c_{t}^{m}+\Delta s_{t}+v_{t}^{p x}$

Labour supply decision

$w_{t}-p_{t}-\gamma\left(c_{t}-\eta c_{t-1}\right)=\varphi n_{t}$ 
$w_{t}-p_{t}=\varphi\left(y_{t}-a_{t}\right)+\gamma\left(c_{t}-\eta c_{t-1}\right)(\mathrm{A} 16)$

Real domestic marginal cost (the real wage divided by marginal productivity of labour)

$m c_{t}=\gamma\left(c_{t}-\eta c_{t-1}\right)+\varphi n_{t}-a_{t}$

or

$m c_{t}=\gamma\left(c_{t}-\eta c_{t-1}\right)+\varphi y_{t}-(\varphi+1) a_{t}$

Real marginal cost of imported goods

$m c_{t}^{m}=s_{t}+p_{t}^{*}-p_{t}$

or

$m c_{t}^{m}=\Delta s_{t}+\pi_{t}^{*}-\pi_{t}+m c_{t-1}^{m}$

The Taylor rule describing monetary policy

$i_{t}=\phi_{y} y_{t-1}+\phi_{\pi} \pi_{t-1}+\phi_{i} i_{t-1}+\varepsilon_{t}^{i}$

\section{Endnotes}

1. See for instance Bacchetta and van Wincoop (2006) for an explanation based on information imperfections.

2. Readers who want a detailed derivation of open economy models are referred to Corsetti and Pesenti (2005).

3. Recently, China has emerged as one of Australia's major trading partners. However, there is no good quality quarterly Chinese data on GDP and prices for the sample period. Some of the impact of the Chinese economy will instead presumably be absorbed by the exogenous demand shock for Australian exports.

4. The variance decomposition is for the model variables, not the observable time series. For time series that are estimated to contain only a small measurement error component, the numbers in Table 3 are also a relatively accurate approximation to the variance decomposition of the observed times series.

5. The model without measurement errors was estimated using real GDP as the only indicator for domestic output. More details of the model estimates without measurement errors are available from the author upon request.

\section{References}

Alvarez, L. J., Dhyne, E., Hoeberichts, M. M., Kwapil, C., Le Bihan, H., Lunneman, P., Martins, F., Sabbatini, R., Stahl, H., Vermeulen, P. and Vilmunen, J. 2005, 'Sticky price in the euro area: A summary of new micro evidence', European Central Bank Working Paper Series no. 563.

An, S. and Schorfheide, F. 2007, 'Bayesian analysis of DSGE models', Econometric Reviews, vol. 26, pp. 113-72.

Bacchetta, P. and van Wincoop, E. 2006, 'Can information heterogeneity explain the exchange rate determination puzzle?', American Economic Review, vol. 96, pp. 552-76.

Benigno, P. 2001, 'Price stability with imperfect financial integration', Centre for Economic Policy Research Working Paper no. 2854, London.

Berkelmans, L. 2005, 'Credit and monetary policy: An Australian SVAR', Reserve Bank of Australia Research Discussion Paper no. rdp2005-06, Sydney.

Bils, M. and Klenow, P. J. 2004, 'Some evidence on the importance of sticky prices', Journal of Political Economy, vol. 112, pp. 947-85.

Boivin, J. and Giannoni, M. 2006, 'DSGE models in a data-rich environment', National Bureau of Economic Research Working Paper no. 12772, Cambridge, Massachusetts.

Composition of Trade 2005, Department of Foreign Affairs and Trade Technical Report, viewed January 2006, $<$ http://www.dfat.gov.au/publications/>.

Corsetti, G. and Pesenti, P. 2005, 'The simple geometry of transmission and stabilization in closed and open economies', National Bureau of Economic Research Working Paper no. 11341, Cambridge, Massachusetts.

Dungey, M. and Pagan, A. 2000, 'A structural VAR model of the Australian economy', Economic Record, vol. 76, pp. 321-42.

Fukac, M., Pagan, A. and Pavlov, V. 2006, 'Econometric issues arising from DSGE models', unpublished manuscript, Australia National University.

\footnotetext{
C ${ }_{2009}$ The University of Melbourne, Melbourne Institute of Applied Economic and Social Research
} 
Gali, J. and Monacelli, T. 2005, 'Monetary policy and exchange rate volatility in a small open economy', Review of Economic Studies, vol. 72, pp. 707-34.

Hansen, L. and Sargent, T. 2005, Recursive Methods for Linear Economies, University of Chicago and New York University.

Justiano, A. and Preston, B. 2005, 'Can structural open economy models account for the influence of foreign disturbances', unpublished manuscript, Columbia University.

Kam, T., Lees, K. and Liu, P. 2006, 'Uncovering the hit-list for small inflation targeters: A Bayesian structural analysis', Reserve Bank of New Zealand Discussion Paper DP 2006/09, Wellington.

Lubik, T. and Schorfheide, F. 2005, 'A Bayesian look at new open economy macroeconomics', Department of Economics Eco- nomics Working Paper Archive no. 521, Johns Hopkins University.

Lubik, T. and Schorfheide, F. 2007, 'Do central banks respond to exchange rate movements? A structural investigation', Journal of Monetary Economics, vol. 54, pp. 1069-87.

Nessen, M. 2006, 'How are DSGE models used in policy-making?', paper presented to Reserve Bank of New Zealand Conference. The Interface between Monetary Policy and Macro Modelling, Wellington, 13-15 March.

Smets, F. and Wouters, R. 2003, 'An estimated stochastic general equilibrium model of the euro area', Journal of the European Economic Association, vol. 1, pp. 1123-75.

Soderlind, P. 1999, 'Solution and estimation of RE macromodels with optimal policy', European Economic Review, vol. 43, pp. 81323. 